\section{Genes should not be patentable, but if they are, we all have to do it}

Sir- Public debate about advances in molecular biology and the billion-dollar revenues that may accrue from new therapies has taken on particular significance in Brazil. This is a result of the enormous success of the consortium which reported the genetic sequencing of Xylella fastidios $a^{1}$, the bacterium causing the 'amarelinho' disease that destroys more than $30 \%$ of São Paulo's orange groves.

The same consortium is making great sequencing progress in three other areas: human cancer genes endemic to Brazil; genes related to sugar-cane metabolism; and the genome of the Xanthomonas citri bacterium which causes citric cancer, widespread in Brazil's orange groves.

Brazilian discoveries need to be protected, but the country's legislation does not permit the patenting of live beings. Brazilians are inexperienced in dealing with international patents. Of the 100,000 or so patents granted by the United States patenting office each year, a mere few dozen go to Brazilians.

Every original invention that is useful and has a commercial potential can be patented somewhere in the world. Human imagination knows no bounds: take, for example, US patent 5443036, a device for encouraging a cat to exercise by chasing a light spot ${ }^{2}$. However, the US statutes define four types of inventions for purposes of registration: new processes (or methods); machines (or devices); manufactured articles; and new compositions of matter.

Processes or methods are inventions that describe how to do something. A typical claim could be "a method to make vegetable soup", which comprises all the necessary steps for preparation. Devices are machines that do something, such as "brush teeth automatically", followed by a description of the parts that make them up and how they interrelate. An example in the third category might be an "optical fibre", with a detailed description of its structure and composition.

In the fourth category, although matter existing spontaneously in nature is not patentable, new compounds and chemical compositions can be. Thus, a synthesized bioactive glass for the substitution of bones and teeth, containing oxygen, silicon, sodium, calcium and phosphorus, has been patented ${ }^{3}$. But its constituent elements, being natural, cannot. (One can imagine the possible consequences had each element of the periodic table been patented following discovery.)

A patent requires human intervention in the design, construction and synthesis or manufacture of the product. Another requirement is descriptive sufficiency: enough information for the invention to be reproduced. Hence there is a clear difference between invention and discovery. The former results in a new composition, product, device or process; the latter from the unveiling of universal laws or from the structure or composition of extant natural matter.

Powerful lobbies have encouraged the filing of patents on live beings. North American and European agencies - with the exception of the French - have granted several thousand patents for genes and genomes, despite the promises of world leaders. The most common argument is that patents will be granted only after the gene's functionality has been clearly established. But surely this is a question of discovery, not invention?

From an ethical standpoint, genes should not be patented (although medical inventions based on such a discovery can and should be). Yet in industrialized countries researchers are filing thousands of gene patents: Celera Genomics alludes to 6,500 . So how should Brazil, or any country, protect the public resources that make these discoveries possible? Until logic and common sense prevail, we should patent our inventions everywhere. However, one could deposit discoveries that might have immediate commercial interest in electronic databases and charge for privileged access. This would not prevent other investigators continuing their research, even if they could not afford privileged access to the latest discoveries. Edgar Dutra Zanotto

7-09-00 Federal University of São Carlos, 13.565905, São Carlos, São Paulo, Brazil

1. X. fastidiosa Consortium Nature 406, 151-157 (2000).

2. Amiss, K. T. \& Abbott, M. H. Method of exercising a cat. US Patent 5443036 (1995).

3. Hench, L. et al. Bioactive ceramics and method of preparing bioactive ceramics. US Patent 5981412 (1997).

\section{Results may not fit well with current theories ...}

Sir - There is a narrow inevitability about Partridge and Barton's response ${ }^{1}$ to True and Lindquist's evolutionary interpretation of their remarkable finding: that the presence of the yeast prion $\left[\mathrm{PSI}^{+}\right]$releases cryptic phenotypic variation which allows cells to thrive in fluctuating environments and which may facilitate the establishment of new traits ${ }^{2}$.

Partridge and Barton hover between dismissal and marginalization — the last resting place of many new discoveries of genome and developmental dynamics that do not fit easily with the simplistic notion of so-called 'modern' Darwinism that DNA mutation and recombination are the sole heritable changes of state of concern to selection.

What is at stake is whether heritable prion-induced variability in protein size is just a "side effect of disrupted gene expression" or an evolved system for the release of phenotypic variation. Have biological systems evolved evolvability?

The yeast prion case is but the latest example in a long list of ways by which organisms increase variation during the intricate processes of transforming genotypic information into phenotypes. There is no need to remind Nature's molecular genetics readers of the total phenomenology of differential promoter utilization, DNA modification, differential DNA and RNA splicing, RNA editing, and post-translational modification. To these, we can now add Lindquist's earlier report of stress-induced release of variation via heat-shock protein chaperones ${ }^{3}$ and the $\left[P S I^{+}\right]$story.

All such systems — such as the DNA-based systems of recombinational variation released by sex, the proofreading systems involved with DNA replication, and genetic redundancy resulting from genomic turnover have surely been influenced willy-nilly by selection to produce an exploitable balance between the eternal contrasting needs of stasis and change 4 .

The complex systems of proteins and RNA that are part of such multiple checks and balances are not just side effects of something else supposedly more fundamental and selectable - they are of the essence of responsive developmental processes. Either all of these systems facilitate evolution or they all don't. Given our current ignorance, we can't pick and choose.

Gabby Dover

Department of Genetics, University of Leicester,

University Road, Leicester LE1 7RH, UK

1. Partridge, L. \& Barton, N. H. Nature 407, 457-458 (2000).

2. True, H. L. \& Lindquist, S. L. Nature 407, 477-483 (2000).

3. Rutherford, S. L. \& Lindquist, S. L. Nature 396, 336-342 (1998).

4. Dover, G. A. Dear Mr Darwin: Letters on the Evolution of Life and Human Nature (Weidenfeld and Nicolson, London, 2000).

\section{... but yeast prion offers clues about evolution}

Sir - Partridge and Barton in their News and Views article ${ }^{1}$ on our paper ${ }^{2}$ make many interesting points, but they also misrepresent our hypothesis. Our main hypothesis is not that the yeast prion $\left[\mathrm{PSI}^{+}\right]$is maintained by natural selection because it aids evolution. This was the last of the three 
suggestions in our paper, and the one we least favoured. Partridge and Barton propose, as if it were an alternative view, that the increased variation $\left[\mathrm{PSI}^{+}\right]$produces is "a side effect of disrupted gene expression”. But this is obvious, and we never suggested otherwise.

The main point is that, no matter how it arose or is maintained, the prion has strong and remarkably varied effects on growth. This seems likely to permit survival in fluctuating environments and provides a plausible route to the evolution of new traits.

In our paper, we suggested that a capacity to accumulate silent variation and release it in a combinatorial fashion might facilitate evolutionary change. But this was not the motivation for our work, as suggested by Partridge and Barton. Rather, we asked if this very unusual form of inheritance might provide a selective advantage. It was the extraordinary diversity of the traits we observed that suggested broader implications. We never claimed these traits must be due to "large variations, involving several random changes". Some might be, and this has important implications. But others might be due to something as simple as the addition of a few amino acids to a single kinase that increases its stability or prevents association with a repressor.

Finally, we did not suggest that "there is no path by which natural selection could construct [complex adaptations]." We are simply not convinced that stepwise, individually selected nondeleterious pathways are sufficient to explain all evolution.

When we discovered in earlier work that Hsp90 has a massive capacity to buffer morphogenetic variation and release that variation in response to environmental stress, we hypothesized that this protein might have a previously unappreciated impact on evolution, as a natural consequence of its special role in protein folding. We did not, however, as has been suggested $^{3}$, claim that these properties evolved to this end.

It is disappointing that in many US schools the doctrine of creationism is given equal weight with the theory of evolution (see, for example, ref. 4). Plausible explanations for the sometimes puzzlingly rapid pace of evolution may help to counter arguments that evolution cannot have done what it is held to have done.

\section{Susan Lindquist}

Department of Molecular Genetics and Cell Biology, Howard Hughes Medical Institute,

University of Chicago, Chicago, Illinois 60637, USA

1. Partridge, L. \& Barton, N. H. Nature 407, 457-458 (2000)

2. True, H. L. \& Lindquist, S. L. Nature 407, 478-483 (2000).

3. Dickinson, W. J. \& Seger, J. Nature 396, 336-342 (1998).

Lerner, S. L. Nature 407, 287-290 (2000).

\section{In defence of Spanish R\&D spending}

Sir - Your editorial on the 2001 Spanish budget for science and technology (Nature 407, 659; 2000) contains some claims that are far from the real facts. This article, written in sensationalist language, has created much confusion in the Spanish press and in the scientific community, where a claim from Nature - thanks to its well-deserved scientific reputation - is taken as the truth.

The editorial mentions the Spanish government's "secrecy" and says I was "reluctantly forced to admit that more than $50 \%$ of our 2001 R\&D budget will be devoted to military expense". First, there is no secrecy or reluctance. The budget figures - including military research expenditures - are in the public domain, and I have explained them in the Congress, in the Senate and in press conferences.

Second, I never said that over half of our R\&D budget is spent on defence, as this is simply not true.

It is misleading to mix expenditures on grants in with government loans - money which will one day be returned. Spain's 2001 budget for research and technological programmes will be managed mostly $(85.5 \%)$ by the new Spanish Ministry of Science and Technology (MST) - only 9.3\% will be controlled by the Ministry of Defence. In the MST, the projected research budget, excluding loans, is 1,588 million euros, of this exactly zero will be used in defence programmes. Defence expenditures appear only under our government loans - at zero interest programmes. Here the total is 2,563 million euros, of which 1,447 million euros can be associated with technological investments in defence. These numbers are large in relation to funds allocated to grants, but the implied subsidy is only in the interest-rate differential (and loan maturation) and not the total amount. Defence expenses within our ministry budget will grow at $5.7 \%$, whereas basic research programmes will grow by $10.1 \%$.

One could simply spend less on $R \& D$ defence programmes to spend more elsewhere. This is how things were done in the past. However, the "elsewhere" was geographical, as defence technology was imported from abroad. This situation has changed radically over the past few years. To a large extent, thanks to the support of R\&D defence programmes, Spain now has an innovative, competitive and fastgrowing aeronautics industry that has created new products and jobs.

There are, however, other aspects of the budget that are new. This is the first year since Spain regained democracy that there is no budget deficit. Nevertheless, $R \& D$ expenditures are growing substantially above the average government expenditures of $4.5 \%$. Priority is given to increasing the number of research positions and long-term contracts (more than 800 in 2001, to achieve the 2,000 goal by 2003). Programmes devoted to human resources are planned to grow at $18 \%$, and a further plan will be launched to attract Spanish researchers back from abroad.

One would have expected that Nature, having been concerned about these issues in the past, would have emphasized these priorities and innovations.

Ramón Marimon, Secretary of State for Scientific and Technological Policy, Ministry of Science and Technology, Paseo de la Castellana 160, E-28071, Madrid, Spain

\section{Don't ignore the risk of vaccine contamination}

Sir - Your News and Opinion articles ${ }^{1,2}$ about alleged contamination of vaccines should serve as a warning against over-optimism.

These articles highlight the failure to show any evidence for contamination of Wistar Institute polio vaccine stocks by human and simian immunodeficiency viruses (HIV/SIV), and you appeal for a truce. But - although Edward Hooper is quoted as saying that "vaccine samples released did not include any from batches prepared for use in Africa" - lymphocytes have been detected in other polio vaccines ${ }^{3}$. Half of the vervet monkeys in Southern Africa are SIV positive; these animals were used for preparing early polio vaccines.

Considering the many millions of vaccine doses prepared in primary vervet monkey kidney cultures over a 30-year period, it is inconceivable that some SIV did not contaminate many cultures. By the same yardstick, simian virus 40 (SV40) contaminated millions of doses of poliovirus vaccine until the animals were screened for this tumour virus.

Edward Hooper and others surely do not intend to undermine the polio vaccine efforts. What is needed is a new awareness of the need for caution - remembering the example of BSE - in view of the current impetus towards xenotransplantation and the accompanying danger of contamination. Our aim should be to improve our vaccines, not to undermine public confidence in them.

\section{G. Lecatsas}

Department of Virology, Medical University of Southern Africa, Medunsa 0204, South Africa

\footnotetext{
1. Nature 407, 115 (2000).

2. Dickson, D. Nature 407, 117 (2000).

3. Ohta, Y. et al. AIDS 3, 183-184 (1989).
} 